\title{
Preparation of Porous MnO@C Core-Shell Nanowires as Anodes for Lithium-Ion Batteries
}

\author{
Shouhui Chen, ${ }^{1}$ Yaqin Chen, ${ }^{1}$ Rihui Zhou, ${ }^{1}$ Jiafeng Wu, ${ }^{1}$ Yonggui Song, ${ }^{1,2}$ \\ Ping Li, ${ }^{1}$ Yonghai Song, ${ }^{1}$ and Li Wang ${ }^{1}$ \\ ${ }^{1}$ College of Chemistry and Chemical Engineering, Jiangxi Normal University, 99 Ziyang Road, Nanchang 330022, China \\ ${ }^{2}$ Jiangxi University of Chinese Traditional Medicine, 56 Yangming Road, Nanchang 330006, China
}

Correspondence should be addressed to Shouhui Chen; csh2k@sina.com

Received 23 May 2016; Accepted 4 July 2016

Academic Editor: Seong-Ho Baek

Copyright (C) 2016 Shouhui Chen et al. This is an open access article distributed under the Creative Commons Attribution License, which permits unrestricted use, distribution, and reproduction in any medium, provided the original work is properly cited.

\begin{abstract}
PorousMnO@C core-shell nanowires were prepared via a simple and facile method. The morphologies, the phase purity, the mass contents, and the BET surface area of the composite were characterized by SEM, XRD, TGA, and $\mathrm{N}_{2}$ adsorption test, respectively. When the composite served as an anode for lithium-ion batteries, it showed superior electrochemical performances. The MnO@C composite presented a reversible capacity of $448.1 \mathrm{mAh} \mathrm{g}^{-1}$ after 100 cycles at the current rate of $200 \mathrm{~mA} \mathrm{~g}^{-1}$.
\end{abstract}

\section{Introduction}

With the rapid development of electronic information industry, as well as the existing problem of the depletion of natural resources and environmental deterioration, developing renewable energy and environment-friendly energy was one of the most important fields in the development of new energy storage technology. Meanwhile, much attention has been paid for the new generation of lithium-ion batteries (LIBs) with high energy density and high power density [1]. Traditionally, the anode for LIBs was graphite having a theoretical capacity of $372 \mathrm{mAh} \mathrm{g}^{-1}$. Nowadays, many transitional metal oxides were considered as alternative anode materials for LIBs [2-4]. For example, manganous oxide $(\mathrm{MnO})$ has a theoretical capacity of $755 \mathrm{mAh} \mathrm{g}^{-1}$ [5], which is almost twice as large as that of graphite. To achieve the target of high performance in LIBs, $\mathrm{MnO}$ nanoparticles with special nanostructures and special morphologies have been synthesized [5-7].

In recent years, the application of one-dimensional nanometer material in LIBs has become more and more attractive. It was supposed that $1 \mathrm{D}$ nanomaterials could efficiently release the stress from the huge volume change during the discharge-charge process $[8,9]$. Furthermore, nanowires (NWs) and other 1D nanoscale building blocks can be covered by functional materials to improve their electrochemical performance. Carbonaceous materials are excellent coating materials due to their high electric conductivity and high mechanical strength. For instance, Zhang et al. prepared $\mathrm{MnO} / \mathrm{C}$ NWs by pyrolyzing $\mathrm{MnO}_{2}$ /polypyrrole NWs and used them as anode for LIBs [10].

In this paper, $\mathrm{MnOOH}$ nanowires were firstly synthesized via hydrothermal reaction and then coated with a layer of resorcinol-formaldehyde (RF) resin. The final product, $\mathrm{MnO} @ \mathrm{C}$ composite, was obtained by pyrolyzing $\mathrm{MnOOH} @ \mathrm{RF}$ in $\mathrm{N}_{2}$ atmosphere. Then the composites were characterized via scanning electron microscopy (SEM), X-ray diffraction (XRD), and thermogravimetric analysis (TGA). It was used as an anode for the lithium-ion batteries, and the electrochemical performances were investigated by cyclic voltammetry and galvanostatic discharge-charge test.

\section{Experimental}

2.1. Materials. Potassium permanganate $\left(\mathrm{KMnO}_{4}\right)$ was obtained from Nachang Xinguang Chemical Factory. Resorcinol, formaldehyde solution (38\%), ammonia aqueous solution $\left(\mathrm{NH}_{3} \cdot \mathrm{H}_{2} \mathrm{O}, 25 \%\right)$, and ethanol were purchase from Sinopharm Chemical Reagent Co., Ltd. All chemicals were used directly without further purification. 


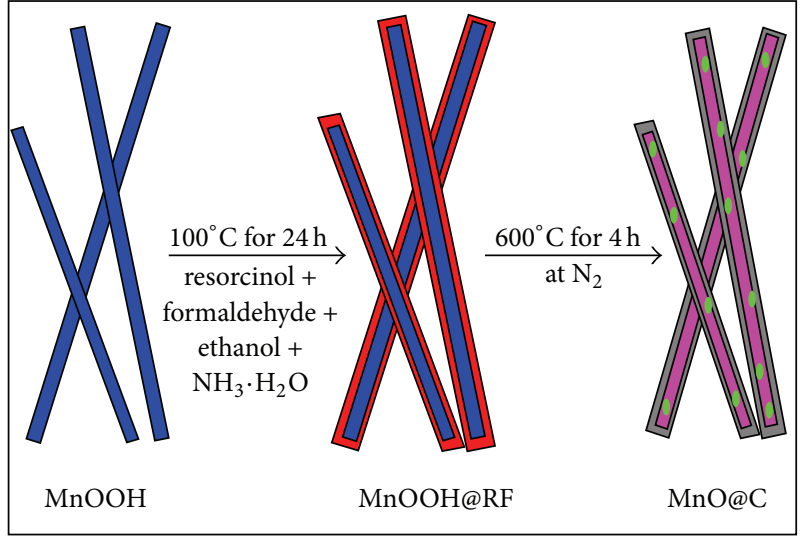

FIGURE 1: Schematic illustration of preparing MnO@C.

\subsection{Preparation of Porous $\mathrm{MnOOH}$ Nanowires. $\mathrm{MnOOH}$} NWs were synthesized according to a modified procedure described by Zhao et al. [11]. In short, $2.7000 \mathrm{~g}$ of $\mathrm{KMnO}_{4}$, $60.00 \mathrm{~mL}$ of $\mathrm{H}_{2} \mathrm{O}$, and $4.50 \mathrm{~mL}$ of ethanol were mixed together. Then the solution was transferred into a $100 \mathrm{~mL}$ autoclave and kept at an electronic oven at $150^{\circ} \mathrm{C}$ for 20 hours. After cooling down, the precipitation was collected by centrifugation, repeatedly washed with ethanol and $\mathrm{H}_{2} \mathrm{O}$, and dried at $60^{\circ} \mathrm{C}$ overnight.

2.3. Preparation of Porous $\mathrm{MnO} @ \mathrm{C}$ Nanowires. $\mathrm{MnO} @ \mathrm{C}$ NWs were prepared as Figure 1 illustrated. Firstly, $0.3160 \mathrm{~g}$ of $\mathrm{MnOOH}$ was dispersed in a solution containing $0.2000 \mathrm{~g}$ of resorcinol, $280 \mu \mathrm{L}$ of formaldehyde solution, $200 \mu \mathrm{L}$ of ammonia aqueous solution, $40.00 \mathrm{~mL}$ of ethanol, and $40.00 \mathrm{~mL}$ of $\mathrm{H}_{2} \mathrm{O}$. Then the solution was placed in a Teflonsealed autoclave and kept at $100^{\circ} \mathrm{C}$ for 24 hours. The precipitation, $\mathrm{MnOOH} \mathrm{NWs}$ coated with resorcinol-formaldehyde resin $(\mathrm{MnOOH} @ \mathrm{RF})$, was collected via centrifugation-rinse cycles. After drying at $60^{\circ} \mathrm{C}$ overnight, MnOOH@RF NWs were calcined to obtain $\mathrm{MnO} @ \mathrm{C} \mathrm{NWs}$ at $600^{\circ} \mathrm{C}$ for 4 hours in $\mathrm{N}_{2}$ atmosphere. For comparison, $\mathrm{Mn}_{2} \mathrm{O}_{3} \mathrm{NWs}$ were prepared by directly calcining $\mathrm{MnOOH} N W s$ at $600^{\circ} \mathrm{C}$ for 4 hours in air.

2.4. Characterization. The samples' morphologies were scanned by scanning electron microscopy (SEM, Hitachi S-3400N). The crystalline phases of the samples were determined by X-ray diffraction (XRD, Bruker D8 Advance). The mass content of $\mathrm{MnO}$ in the composite was quantified by thermogravimetric analysis (TGA, Perkin-Elmer Diamond TG/DTA). $\mathrm{N}_{2}$ adsorption-desorption isotherm of $\mathrm{MnO} @ \mathrm{C}$ was measured by BELSORP-mini II instrument.

2.5. Electrochemical Measurements. The electrochemical performance of MnO@C NWs was investigated using button batteries (CR2032). The batteries were composed of lithium foil (the reference and counter electrode) and the $\mathrm{MnO} @ \mathrm{C}$ working electrode, which were separated by a microporous polypropylene separator soaked in an electrolyte of $1.0 \mathrm{~mol}$

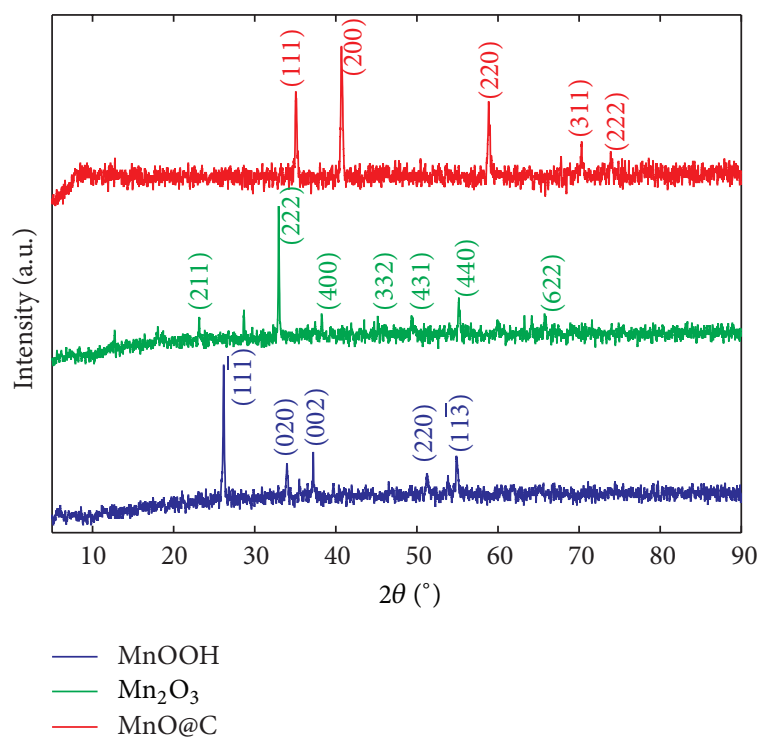

FIGURE 2: XRD patterns of $\mathrm{MnOOH}$ and $\mathrm{MnO} @ \mathrm{C}$.

$\mathrm{L}^{-1} \mathrm{LiPF}_{6}$ dissolved in ethylene carbonate/dimethyl carbonate (1:1 by volume). The $\mathrm{MnO} @ \mathrm{C}$ electrode was prepared by pasting slurry on copper foil. The slurry was mixed with polyvinylidene fluoride, carbon black, and the $\mathrm{MnO} @ \mathrm{C}$ composite (1:1:8 by mass) in N-methyl-2-pyrrolidinone. The loading mass of the active materials on copper foil was about $0.47 \mathrm{mg} \mathrm{cm}^{-2}$. The batteries were galvanostatically tested on a multichannel batteries testing system (Land CT2001A). Cyclic voltammetry (CV) was recorded on an electrochemical workstation (CHI760E).

\section{Results and Discussion}

3.1. Characteristics of $\mathrm{MnO} @ \mathrm{C}$. The phase purity of the samples was characterized by XRD. As shown in Figure 2, the hydrothermal product of the solution containing $\mathrm{KMnO}_{4}$ and ethanol was $\mathrm{MnOOH}$, whose XRD pattern was consistent with the JCPDS card number 41-1379 [12]. The direct pyrolysis product of $\mathrm{MnOOH}$ NWs in air was $\mathrm{Mn}_{2} \mathrm{O}_{3}$, which was confirmed by the series of XRD peaks in the figure (JCPDS card number 41-1442). The pyrolysis product of $\mathrm{MnOOH} @ \mathrm{RF}$ NWs had different XRD patterns. The peaks at $2 \theta=35.1,40.7$, $58.9,70.3$, and $73.9^{\circ}$ could be well indexed to the (111), (200), (220), (311), and (222) planes of MnO (JCPDS number 070230) [13], which indicated $\mathrm{MnOOH}$ had turned to $\mathrm{MnO}$, and the carbon generated from RF resin provided a reduction atmosphere in the pyrolysis.

The morphologies of the samples were displayed in Figure 3. Both sample $\mathrm{MnOOH}$ and sample $\mathrm{MnO} @ \mathrm{C}$ presented nanowires characteristic. As shown in Figure 3(a), most of sample $\mathrm{MnOOH}$ was nanowires with the diameters in range of $0.2 \sim 0.7 \mu \mathrm{m}$ and the lengths over $28 \mu \mathrm{m}$. And the surface of $\mathrm{MnOOH}$ NWs was smooth. MnO@C NWs were derived from $\mathrm{MnOOH} \mathrm{NWs}$ (Figure 3(b)), their diameters were distinctively larger than those of $\mathrm{MnOOH}$ NWs, and their surface was rougher than that of $\mathrm{MnOOH}$ NWs. It suggested that carbon had covered $\mathrm{MnO}$ NWs. 


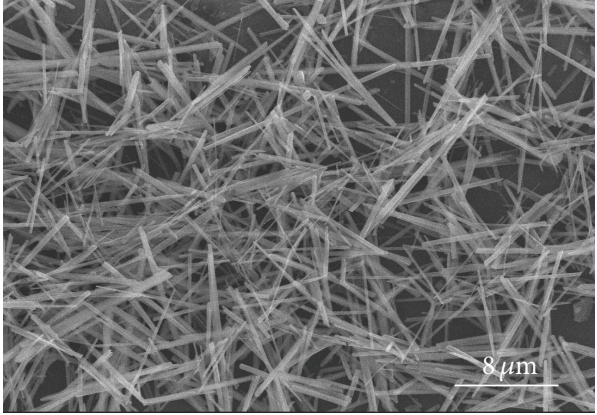

(a)

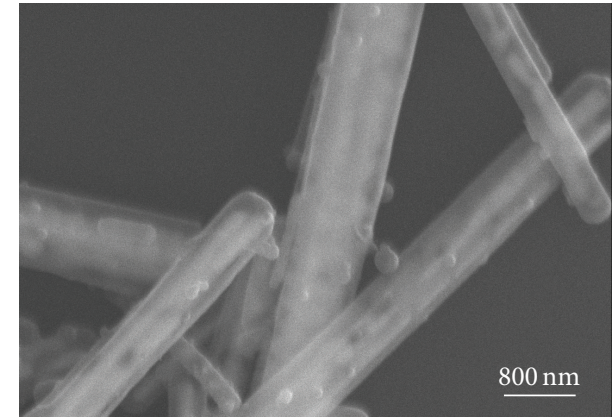

(b)

Figure 3: SEM images of (a) $\mathrm{MnOOH}$ and (b) MnO@C.

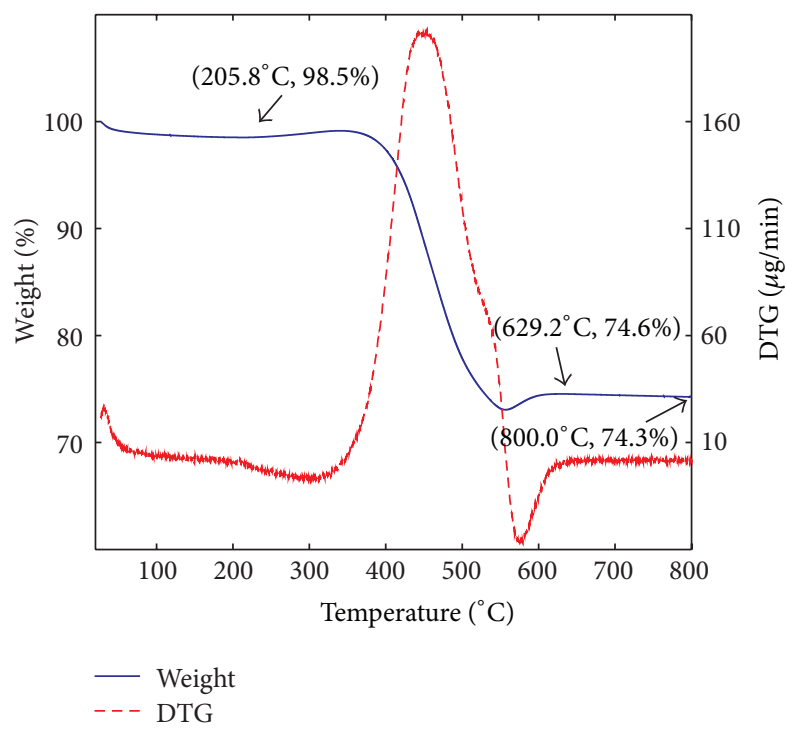

FIgUre 4: TGA plot of $\mathrm{MnO} @ \mathrm{C}$.

The mass content of components could be evaluated by TGA at air atmosphere (Figure 4). The weight of $\mathrm{MnO} @ \mathrm{C}$ NWs slightly decreased until $205.8^{\circ} \mathrm{C}$, which should be ascribed to the evaporation of water adsorbed in the pore of the sample. It fluctuated from 205.8 to $629.2^{\circ} \mathrm{C}$, in which the oxidation of $\mathrm{MnOOH}$ and $\mathrm{RF}$ resin resulted in the weight increase and decrease, respectively. The weight turned to steady when the temperature was beyond $629.2^{\circ} \mathrm{C}$, indicating that $\mathrm{MnOOH} @ \mathrm{RF}$ had thoroughly oxidized to $\mathrm{Mn}_{2} \mathrm{O}_{3}$ [14] . According to the weight of $98.5 \%$ at $205.8^{\circ} \mathrm{C}$ and the weight of $74.3 \%$ at $800.0^{\circ} \mathrm{C}$ shown in the figure, the mass contents of $\mathrm{MnO}$ and carbon calculated were $67.7 \%$ and $32.3 \%$, respectively.

The textures of samples were measured by $\mathrm{N}_{2}$ adsorptiondesorption isotherm. The $\mathrm{MnO} @ \mathrm{C}$ sample presented a typical IV isotherm with H3 hysteresis loop (Figure 5) [15], which implied the mesoporous structure in it. The BET surface area and the total pore volume of $\mathrm{MnO} @ \mathrm{C}$ were $249 \mathrm{~m}^{2} \mathrm{~g}^{-1}$ and $0.188 \mathrm{~cm}^{3} \mathrm{~g}^{-1}$, respectively. They were much larger than those of $\mathrm{MnOOH}\left(2.67 \mathrm{~m}^{2} \mathrm{~g}^{-1}\right.$ and $0.0197 \mathrm{~cm}^{3} \mathrm{~g}^{-1}$, resp.). The larger

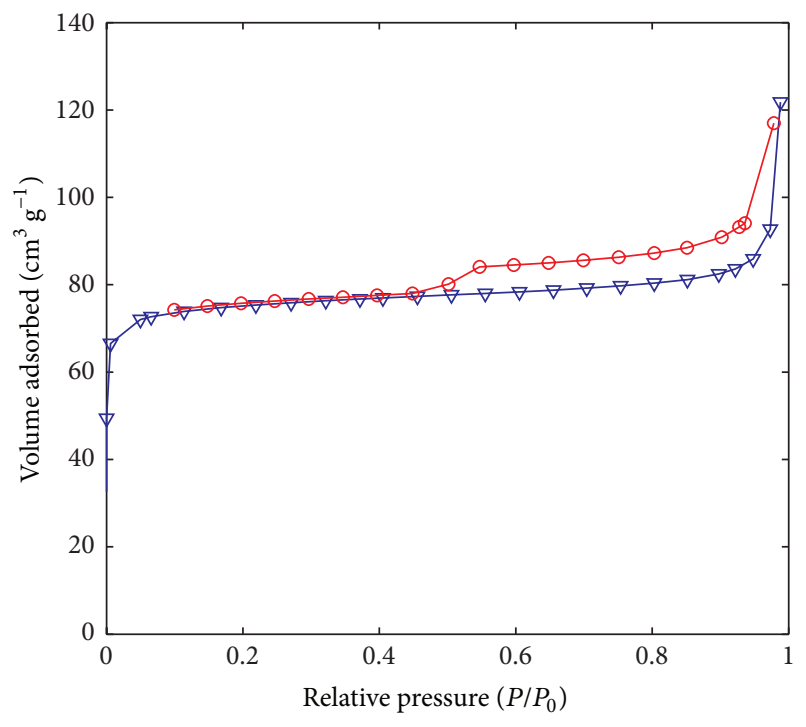

Figure 5: $\mathrm{N}_{2}$ adsorption-desorption isotherm of $\mathrm{MnO} @ \mathrm{C}$.

BET surface area and the larger total pore volume should be attributed to RF resin covered on $\mathrm{MnOOH}$ NWs. During the pyrolysis, $\mathrm{MnOOH} @ \mathrm{RF}$ NWs released $\mathrm{CO}_{2}$ and $\mathrm{H}_{2} \mathrm{O}$ and generated $\mathrm{MnO} @ \mathrm{C}$ NWs with the mesoporous structure.

3.2. Electrochemical Performance of the $\mathrm{MnO} @ \mathrm{C}$ Anode. Sample MnO@C anode was investigated in an assembled coin-type half cell by cyclic voltammogram and galvanostatic discharge-charge test. The electrochemical mechanism of $\mathrm{MnO} @ \mathrm{C}$ during the discharge-charge process was estimated by cyclic voltammetry in the voltage range of $0.01 \sim 3.00 \mathrm{~V}$ at a scan rate of $0.2 \mathrm{mV} \mathrm{s}^{-1}$. As shown in Figure 6, in the first negative scan, the peak around $0.60 \mathrm{~V}$ should be ascribed to irreversible decomposition of the electrolyte and the formation of solid electrolyte interface (SEI) film, which disappeared in the following cycles. The reduction peak between 0.12 and $0.51 \mathrm{~V}$ and the oxidation peak at $1.28 \mathrm{~V}$ could be expressed as the following equation $[16,17]$ :

$$
2 \mathrm{Li}^{+}+\mathrm{MnO}+2 \mathrm{e}^{-} \rightleftharpoons \mathrm{Mn}+\mathrm{Li}_{2} \mathrm{O} .
$$




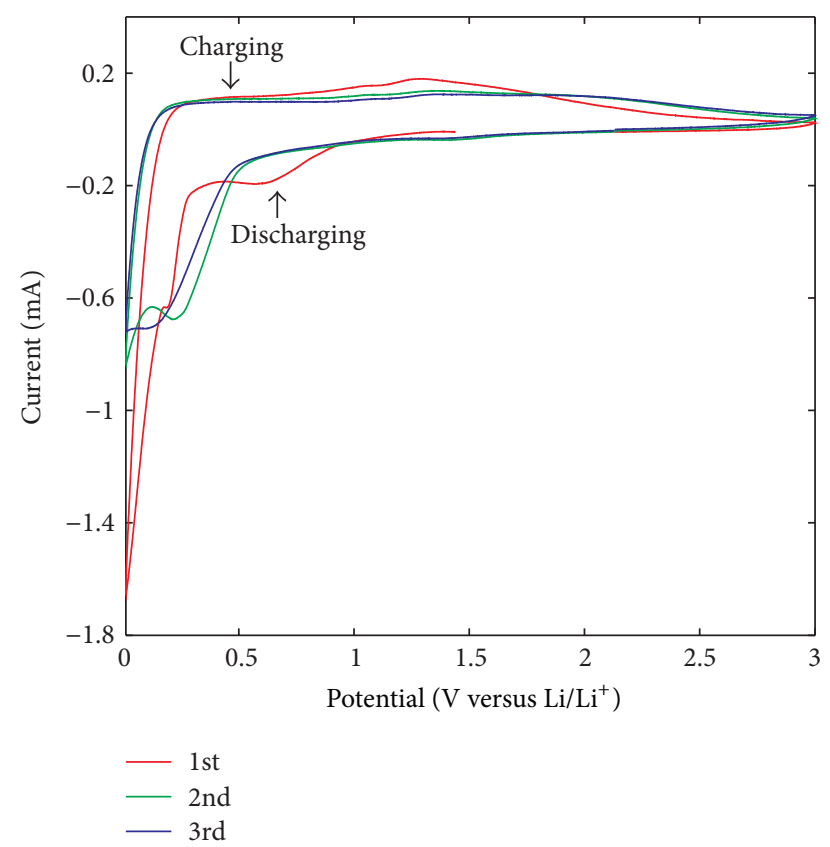

FIGURE 6: Cyclic voltammogram of MnO@C between 0.01 and $3.00 \mathrm{~V}$ at a scan rate of $0.2 \mathrm{mV} \mathrm{s}^{-1}$.

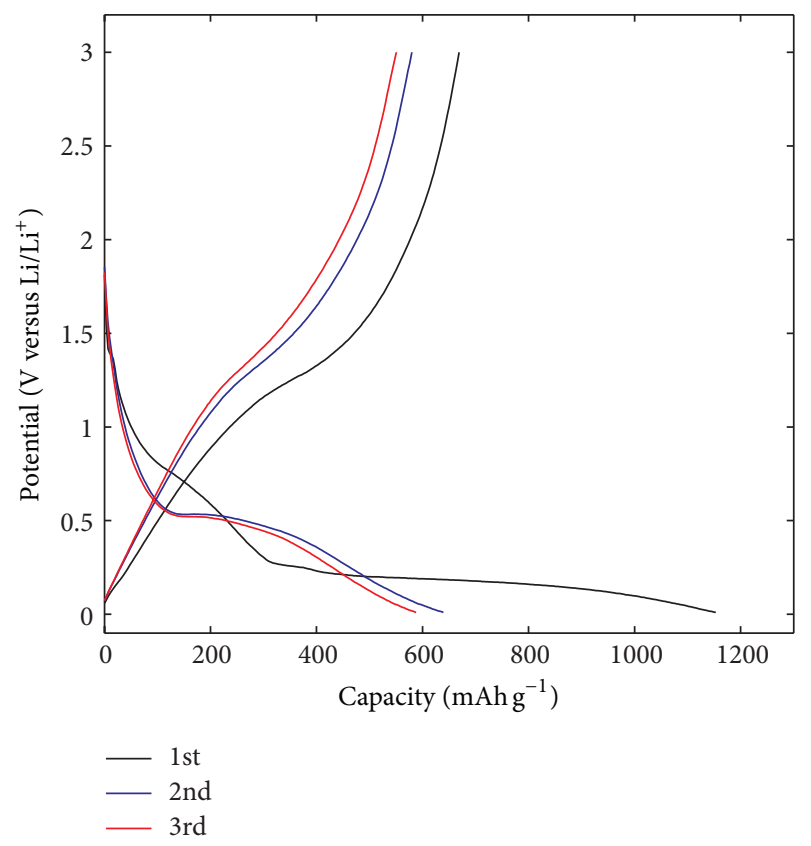

FIGURE 7: Voltage profile of MnO@C between 0.01 and 3.00 V during the first three discharge-charge cycles at a current rate of $200 \mathrm{~mA} \mathrm{~g}^{-1}$.

Since the second cycle, the CV curves tended to overlap, indicating a stable and reversible electrochemical behavior of MnO@C anode.

Figure 7 showed the voltage profile of $\mathrm{MnO} @ \mathrm{C}$ for the first three cycles between 0.01 and $3.00 \mathrm{~V}$ at a current rate of $200 \mathrm{~mA} \mathrm{~g}^{-1}$. It could be seen that a plateau appeared between 0.6 and $0.7 \mathrm{~V}$ in the initial discharge curve, indicating the formation of SEI film. Another long and flat discharge plateau

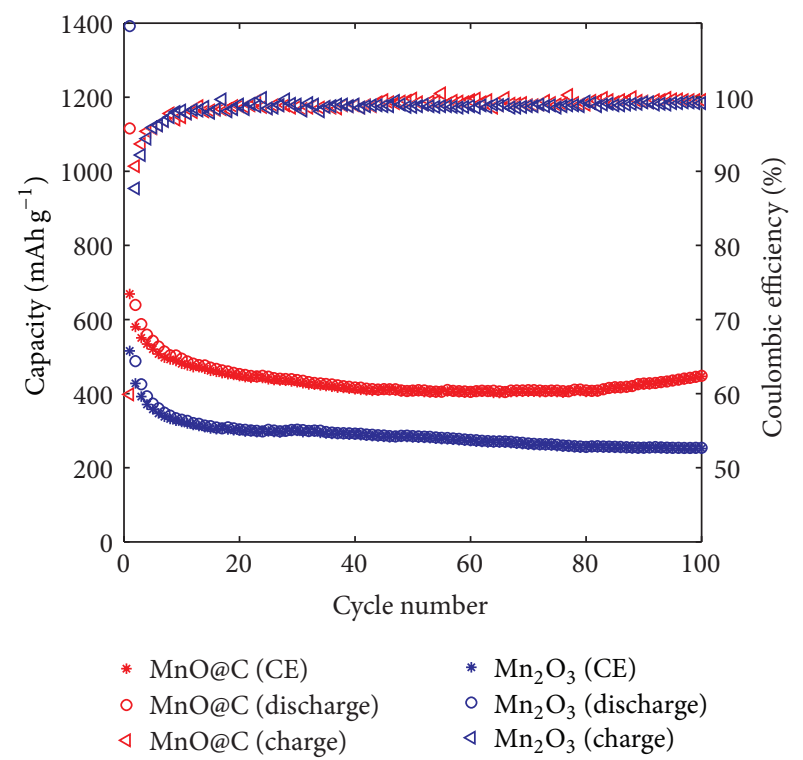

Figure 8: Cycle performance of $\mathrm{MnO} @ \mathrm{C}$ between 0.01 and $3.00 \mathrm{~V}$ at a current rate of $200 \mathrm{~mA} \mathrm{~g}^{-1}$.

appearing at $\sim 0.2 \mathrm{~V}$ was related to the reduction reaction of $\mathrm{Mn}^{2+}$ to $\mathrm{Mn}^{0}$, which shifted to $\sim 0.5 \mathrm{~V}$ since the second cycle $[10,18]$. After that, a plateau from 1.2 to $1.3 \mathrm{~V}$ was revealed on the charge curve, indicating the oxidation of $\mathrm{Mn}$ to $\mathrm{MnO}$. Since the second cycle, the galvanostatic dischargecharge curves turned to almost identical, which was in good agreement with the $\mathrm{CV}$ curves of $\mathrm{MnO} @ \mathrm{C}$.

The galvanostatic discharge-charge test of $\mathrm{MnO} @ \mathrm{C}$ for 100 cycles was shown in Figure 8. The sample MnO@C should have a theoretical capacity of $631.3 \mathrm{mAh} \mathrm{g}^{-1}$ according to the equation

$$
\mathrm{C}_{\mathrm{MnO} @ \mathrm{C}}=\mathrm{m}_{\mathrm{MnO}} \times \mathrm{C}_{\mathrm{MnO}}+\mathrm{m}_{\text {carbon }} \times \mathrm{C}_{\text {carbon }}
$$

in which $\mathrm{m}_{\mathrm{MnO}}$ and $\mathrm{m}_{\text {carbon }}$ were the mass content of $\mathrm{MnO}$ and carbon and the $\mathrm{m}_{\mathrm{MnO}}$ and $\mathrm{m}_{\text {carbon }}$ were the theoretical capacity of $\mathrm{MnO}$ and graphite, respectively. However, at the first cycle, the MnO@C anode delivered a discharge capacity of $1115.8 \mathrm{mAh} \mathrm{g}^{-1}$ which was significantly larger than the theoretical capacity. The larger discharge capacity at the first cycle should result from the irreversible decomposition of the electrolyte and the formation of SEI film as CV suggested. Correspondingly, the fact that the value of discharge capacity was greatly larger than that of the charge capacity led to a low Coulombic efficiency (CE) of only $59.9 \%$ at the first cycle. At the second cycle, the $\mathrm{MnO} @ \mathrm{C}$ anode delivered a discharge capacity of $639.4 \mathrm{mAh} \mathrm{g}^{-1}$, which was close to its theoretical capacity. Since the following cycles, the gradual decrement of discharge capacity came along with the gradual increment of CE. The discharge capacity kept steady around $410 \mathrm{mAh} \mathrm{g}^{-1}$ in the range from the 40th cycle to the 80th cycle. After that, it began to slowly increase. When cycling up to 100 cycles, the MnO@C anode recovered to a discharge capacity of $448.1 \mathrm{mAh} \mathrm{g}^{-1}$. The discharge capacity of $\mathrm{MnO} @ \mathrm{C}$ was larger than that of graphite, which should be attributed 


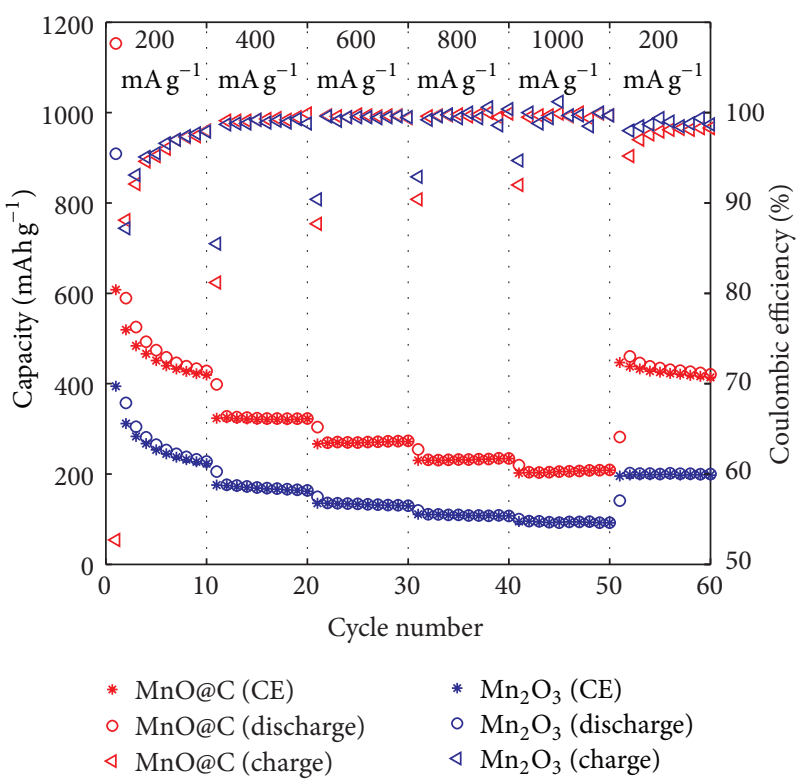

FIGURE 9: Rate capability of MnO@C at the current rate of 200, 400, $600,800,1000$, and $200 \mathrm{~mA} \mathrm{~g}^{-1}$, respectively.

to larger theoretical capacity of $\mathrm{MnO}$ and less aggregation of $\mathrm{MnO}$ nanoparticles in the composite during the dischargecharge cycle [19].

The rate capability of $\mathrm{MnO} @ \mathrm{C}$ was presented in Figure 9. MnO@C anode delivered reversible capacities of 428.1,322.7, 273.4, 234.6, and $209.1 \mathrm{mAh} \mathrm{g}^{-1}$ at the current rates of 200, $400,600,800$, and $1000 \mathrm{mAg}^{-1}$, respectively. When the current rate returned to $200 \mathrm{~mA} \mathrm{~g}^{-1}$, its reversible capacity could recover back to $420.8 \mathrm{mAh} \mathrm{g}^{-1}$, which manifested that the $\mathrm{MnO} @ \mathrm{C}$ anode had a fine rate performance and good reversibility.

In a control experiment, sample $\mathrm{Mn}_{2} \mathrm{O}_{3}$ was also investigated as an anode for LIBs. Although the theoretical capacity of $\mathrm{Mn}_{2} \mathrm{O}_{3}\left(1018 \mathrm{mAh} \mathrm{g}^{-1}\right)$ is larger than that of $\mathrm{MnO}\left(755 \mathrm{mAh} \mathrm{g}^{-1}\right)$, both Figures 8 and 9 showed that the electrochemical performance of sample $\mathrm{MnO} @ \mathrm{C}$ was more superior to that of sample $\mathrm{Mn}_{2} \mathrm{O}_{3}$. The superior electrochemical performance of $\mathrm{MnO} @ \mathrm{C}$ should be attributed to the following reasons: The morphology of sample $\mathrm{MnO} @ \mathrm{C}$ was 1D nanowire, which was helpful to release the stress resulting from the huge volume change during the discharge-charge cycles. The carbon layer on the composite could avoid the aggregation of $\mathrm{MnO}$ nanoparticles in the composite during the discharge-charge cycles. And the carbon layer could also improve the electric conductivity of the whole composite. The composite had mesoporous structure, which could shorten the diffusion length of ion.

\section{Conclusions}

In summary, MnO@C NWs were prepared by a facile, simple, and low cost method. When they acted as anodes for LIBs, they showed a reversible capacity of $448.1 \mathrm{mAh} \mathrm{g}^{-1}$ at a current rate of $200 \mathrm{~mA} \mathrm{~g}^{-1}$ after being cycled for 100 times. Even at a current rate of $1000 \mathrm{~mA} \mathrm{~g}^{-1}$, its reversible capacity was still as large as $209.1 \mathrm{mAh} \mathrm{g}^{-1}$. The superior electrochemical performance of $\mathrm{MnO} @ \mathrm{C}$ NWs should be ascribed to the mesoporous structure in them and the conductive carbon protect layer on $\mathrm{MnO}$.

\section{Competing Interests}

The authors declare that there are no competing interests regarding the publication of this paper.

\section{Acknowledgments}

This work was financially supported by National Natural Science Foundation of China (21465014 and 21465015), Science and Technology Support Program of Jiangxi Province (20123BBE50104 and 20133BBE50008), Young Scientist Foundation of Jiangxi Province (20122BCB23011), Natural Science Foundation of Jiangxi Province (20142BAB203101), the Ministry of Education by the Specialized Research Fund for the Doctoral Program of Higher Education (20133604110002), and the Ground Plan of Science and Technology Projects of Jiangxi Educational Committee (KJLD14023).

\section{References}

[1] S.-Z. Huang, J. Jin, Y. Cai et al., "Three-dimensional (3D) bicontinuous hierarchically porous $\mathrm{Mn}_{2} \mathrm{O}_{3}$ single crystals for high performance lithium-ion batteries," Scientific Reports, vol. 5, Article ID 14686, 2015.

[2] X. Gu, J. Yue, L. Li, H. Xue, J. Yang, and X. Zhao, "General synthesis of $\mathrm{MnO}_{\mathrm{x}}\left(\mathrm{MnO}_{2}, \mathrm{Mn}_{2} \mathrm{O}_{3}, \mathrm{Mn}_{3} \mathrm{O}_{4}, \mathrm{MnO}\right)$ hierarchical microspheres as lithium-ion battery anodes," Electrochimica Acta, vol. 184, pp. 250-256, 2015.

[3] H. Su, Y.-F. Xu, S.-C. Feng et al., "Hierarchical $\mathrm{Mn}_{2} \mathrm{O}_{3}$ hollow microspheres as anode material of lithium ion battery and its conversion reaction mechanism investigated by XANES," ACS Applied Materials and Interfaces, vol. 7, no. 16, pp. 8488-8494, 2015.

[4] C. Zhang, C. Guo, Y. Wei, and L. Hou, "A simple synthesis of hollow $\mathrm{Mn} 2 \mathrm{O} 3$ core-shell microspheres and their application in lithium ion batteries," Physical Chemistry Chemical Physics, vol. 18, no. 6, pp. 4739-4744, 2016.

[5] C. C. Li, H. Yu, Q. Yan, and H. H. Hng, "Nitrogen doped carbon nanotubes encapsulated $\mathrm{MnO}$ nanoparticles derived from metal coordination polymer towards high performance Lithium-ion Battery Anodes," Electrochimica Acta, vol. 187, pp. 406-412, 2016.

[6] Q. Zhang, W. Wang, D. Jiang, and X. Huang, "Mesoporous activated carbon decorated with $\mathrm{MnO}$ as anode materials for lithium ion batteries," Journal of Materials Science, vol. 51, no. 7, pp. 3536-3544, 2016.

[7] Y. Xiao and M. Cao, "Carbon-anchored MnO nanosheets as an anode for high-rate and long-life lithium-ion batteries," ACS Applied Materials \& Interfaces, vol. 7, no. 23, pp. 12840-12849, 2015.

[8] X. Sun, Y. Xu, P. Ding, M. Jia, and G. Ceder, “The composite rods of $\mathrm{MnO}$ and multi-walled carbon nanotubes as anode materials 
for lithium ion batteries," Journal of Power Sources, vol. 244, pp. 690-694, 2013.

[9] X. Zhao, Y. Du, L. Jin et al., "Membranes of MnO beading in carbon nanofibers as flexible anodes for high-performance lithium-ion batteries," Scientific Reports, vol. 5, Article ID 14146, 2015.

[10] C. Zhang, J.-G. Wang, D. Jin, K. Xie, and B. Wei, "Facile fabrication of $\mathrm{MnO} / \mathrm{C}$ core-shell nanowires as an advanced anode material for lithium-ion batteries," Electrochimica Acta, vol. 180, Article ID 25683, pp. 990-997, 2015.

[11] H. Zhao, X. Liu, Z. Zhang et al., "Preparation of $\beta-\mathrm{MnO}_{2}$ and $\alpha$ $\mathrm{Mn}_{2} \mathrm{O}_{3}$ nanorods via a self-sacrificing template route and their characterization and application," Chemical Journal of Chinese Universities, vol. 36, no. 3, pp. 436-441, 2015.

[12] B.-K. Zou, Y.-Y. Zhang, J.-Y. Wang, X. Liang, X.-H. Ma, and C.$\mathrm{H}$. Chen, "Hydrothermally enhanced $\mathrm{MnO} /$ reduced graphite oxide composite anode materials for high performance lithiumion batteries," Electrochimica Acta, vol. 167, pp. 25-31, 2015.

[13] D. Li, Y. Zhang, L. Li et al., "Polydopamine directed MnO@C microstructures as electrode for lithium ion battery," Science China Chemistry, vol. 59, no. 1, pp. 122-127, 2016.

[14] X. Jiang, W. Yu, H. Wang, H. Xu, X. Liu, and Y. Ding, "Enhancing the performance of $\mathrm{MnO}$ by double carbon modification for advanced lithium-ion battery anodes," Journal of Materials Chemistry A, vol. 4, no. 3, pp. 920-925, 2016.

[15] K. Li, F. Shua, X. Guo, and D. Xue, "High performance porous $\mathrm{MnO} @ \mathrm{C}$ composite anode materials for lithium-ion batteries," Electrochimica Acta, vol. 188, pp. 793-800, 2016.

[16] A. Zheng, X. Yang, X. Wu, L. Zhang, Z. Wen, and G. Liang, "In situ self-developed nanoscale $\mathrm{MnO} / \mathrm{MEG}$ composite anode material for lithium-ion battery," Journal of the Electrochemical Society, vol. 163, no. 5, pp. A722-A726, 2016.

[17] J.-G. Wang, C. Zhang, D. Jin, K. Xie, and B. Wei, "Synthesis of ultralong $\mathrm{MnO} / \mathrm{C}$ coaxial nanowires as freestanding anodes for high-performance lithium ion batteries," Journal of Materials Chemistry A, vol. 3, no. 26, pp. 13699-13705, 2015.

[18] X. Tang, G. Sui, Q. Cai, W. Zhong, and X. Yang, "Novel $\mathrm{MnO} /$ carbon composite anode material with multi-modal pore structure for high performance lithium-ion batteries," Journal of Materials Chemistry A, vol. 4, no. 6, pp. 2082-2088, 2016.

[19] F. Zheng, G. Xia, Y. Yang, and Q. Chen, "MOF-derived ultrafine $\mathrm{MnO}$ nanocrystals embedded in a porous carbon matrix as high-performance anodes for lithium-ion batteries," Nanoscale, vol. 7, no. 21, pp. 9637-9645, 2015. 

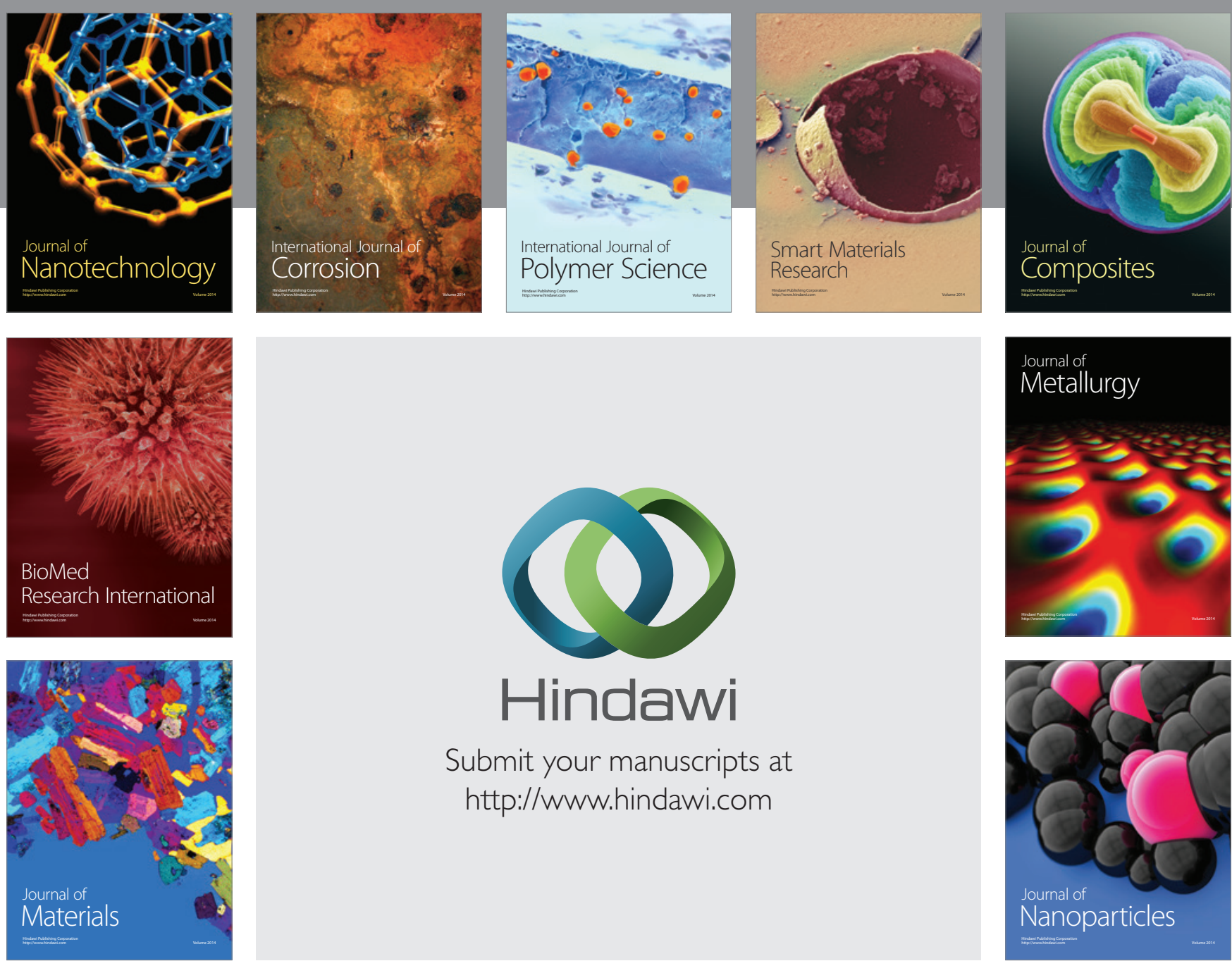

\section{Hindawi}

Submit your manuscripts at

http://www.hindawi.com

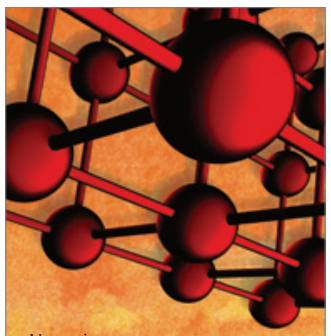

Materials Science and Engineering
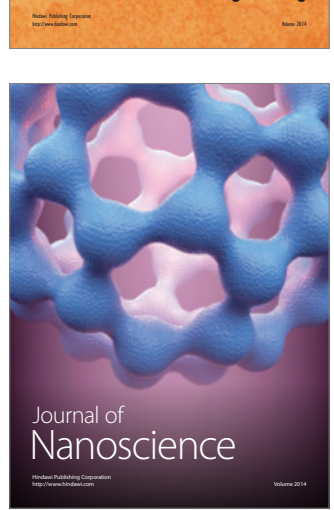
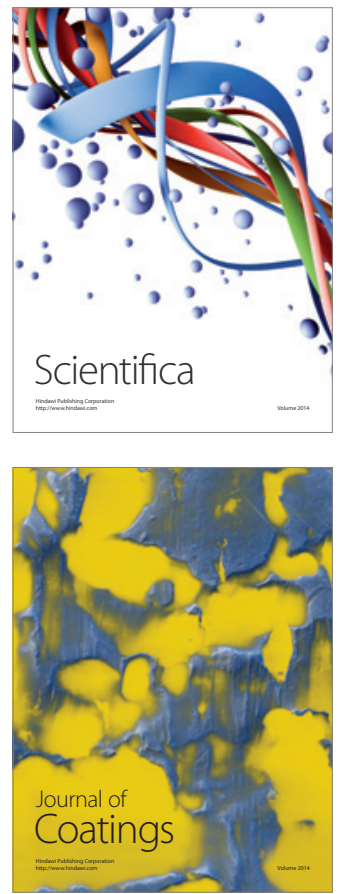
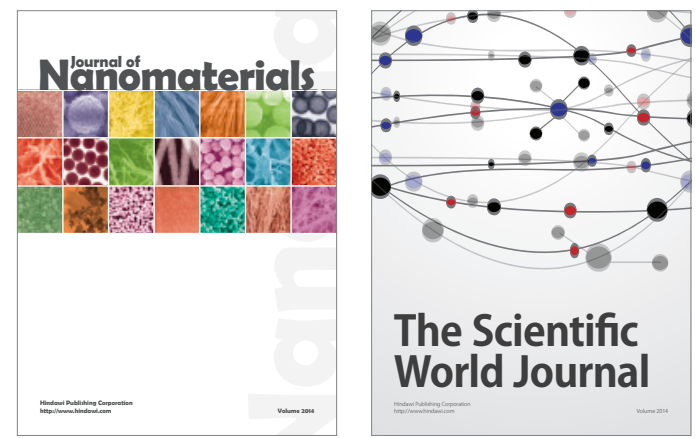

The Scientific World Journal
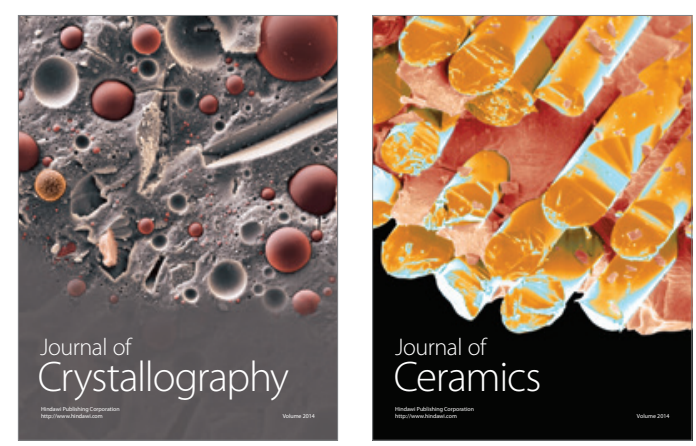
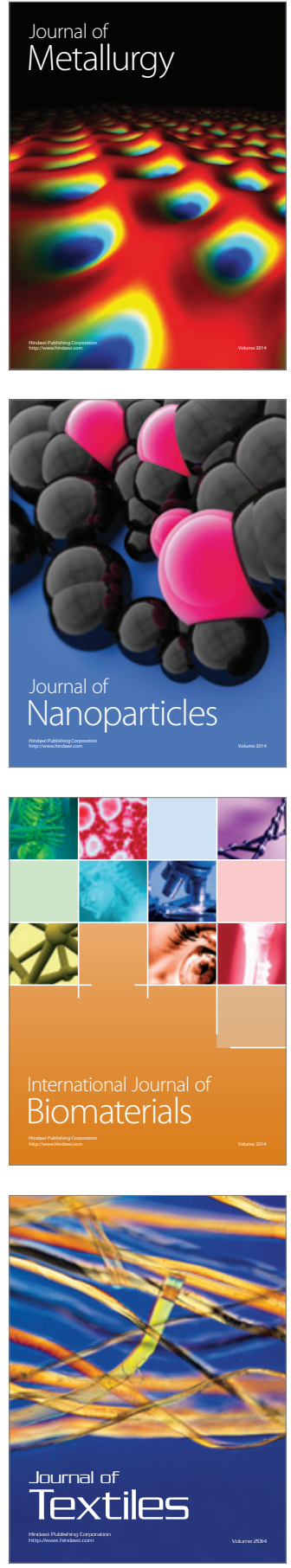